\title{
NO TODO FUE IGUAL. CAMBIOS EN LAS RELACIONES LABORALES, TRABAJO Y NIVEL DE VIDA DE LOS ESPAÑOLES: 1958-1975
}

\author{
Álvaro Soto Carmona
}

No todo fue igual durante el franquismo, algunas de sus bases originales no resistieron su propio desarrollo, hubo cambios importantes que, aunque se explican conociendo sus planteamientos iniciales, no le atan, sino que le permiten modificar el modelo fundacional. La dificultad estriba en explicar lo nuevo, ya que sigue estando presente entre buena parte de los historiadores el «dogma» establecido por Fontana: «lo más conveniente para comprender la naturaleza del franquismo, y para valorar sus consecuencias a largo plazo, es examinarlo en sus comienzos, en 1939, que es cuando se nos aparecen sus propósitos libres de disfraces e interferencias" ${ }^{1}$, pese a estar demostrado que dicho planteamiento es insuficiente para explicar lo realmente sucedido ${ }^{2}$.

Cuando hablamos de economía, durante la dictadura, no hay dudas de que existen dos períodos claramente diferenciados: los primeros quince años son de estancamiento económico y lenta recuperación; los dos decenios siguientes son de rápido crecimiento económico, intensa industrialización y profundo cambio social ${ }^{3}$.

También en el campo político hubo etapas y cambios, de hecho la crisis de Gobierno de 1957, responde plenamente a lo que O'Donnell y Schmitter denominan «replanteamiento conceptual». A partir de dicha crisis, los miembros que forman el Gobierno no responden a su origen político, sino a sus posiciones políticas con respecto a la institucionalización del régimen; ello aporta

1. FONTANA, Josep, "Reflexiones sobre la naturaleza y las consecuencias del franquismo", en FonTANA, Josep (ed.), España bajo el franquismo, Barcelona, 1986, p. 9.

2. Como lucidamente puso de manifiesto Javier TUSELL en el «Prólogo» de mi libro ¿Atado y bien atado? Institucionalización y crisis del franquismo, Madrid, 2005, pp. 13 y 14.

3. TORTELLA, Gabriel, El desarrollo de la España contemporánea. Historia económica de los siglos XIX y XX, Madrid, 1994, p. 204. 
una mayor homogeneidad a la acción de gobierno, aunque no disipa sino que agrava el conflicto intra-régimen, ya que las posiciones políticas en torno a la institucionalización van a mostrar diferencias profundas.

En el ámbito de la historia social, también se pueden apreciar etapas y cambios. Así, poco tienen en común los años de "miseria y hambre» con los del "desarrollismo". Lo mismo ocurre con la estructura ocupacional y sectorial, las formas de trabajo, el modelo de relaciones laborales, los sistemas salariales o el nivel de vida. Estos cambios van modelando una sociedad diferente a la de los años cuarenta, capaz de desarrollar una "cultura cívica» y unas, cada vez más numerosas, "nuevas clases medias".

No cabe duda de que la "apertura" ${ }^{4}$ en el campo de las relaciones laborales fue un complemento previo para la puesta en marcha del Plan de Estabiliza$c^{i o ́ n} n^{5}$, cuyas consecuencias en la economía y la sociedad española fueron muy importantes. La intención de los autores del Plan era combatir «unos cuantos prejuicios -realmente tópicos-» que lastraban la economía española ${ }^{6}$. Se trataba de cambiar la forma de pensar, para lo que era necesario contar con el mayor apoyo posible. Con dicho fin los Ministerios de Hacienda y de Comercio procedieron a realizar una consulta sobre la necesidad de la estabilización económica a diversas instituciones ${ }^{7}$.

Las respuestas de dichas instituciones fueron todas favorables a los cambios que se proponían, excepto la del Instituto Nacional de Industria que seguía aferrado al trasnochado nacionalismo económico. Llama la atención el informe dado por la Organización Sindical Española (OSE), que hizo un canto al europeísmo del recién nacido Mercado Común con un «sesgo de modernidad que no deja de sorprendern ${ }^{8}$.

4. El concepto «apertura» se utiliza sobre todo en Ciencia Política (O'Donnell, Hohlen o Morlino) y supone un cambio en el régimen autoritario, no es un cambio de régimen. Creo que se puede aplicar en el campo de las relaciones laborales con un sentido similar, se trataría de un cambio hacia una mayor democratización de las relaciones laborales, aunque no supone la democratización de las mismas.

5. Decreto Ley 10/1959 del 21 de julio ("Decreto de Ordenación Económica»).

6. Como señalaba Mariano NAVARRO RUBIO: «En primer lugar, el tópico de que la economía estaba subordinada a la política. (...) El segundo prejuicio, en cierto modo derivado del anterior, consistía en el caprichoso argumento de que no hay desarrollo sin inflación, sobre todo en un país que no puede contar con ayudas exteriores. (...) El tercer enemigo era el orgullo que se sentía por la obra realizada con tanto sacrificio. Se confundía el esfuerzo con el éxito. (...) La cuarta dificultad que asimismo existía era una desconfianza alérgica hacia cualquier relación con los organismos internacionales. Se les presentía siempre movidos por torpes designios políticos.”, en Mis memorias, Madrid, 1991, p. 108.

7. Consejo de Economía Nacional, Consejo Superior Bancario, Confederación Española de Cajas de Ahorros, Banco de España, Consejo Superior de Cámaras de Comercio, Organización Sindical Española, Instituto de Estudios Políticos, Instituto Nacional de Industria, Instituto de Estudios Agrosociales, Facultad de Ciencias Económicas y Real Academia de Ciencias Morales y Políticas. Dicha documentación se halla publicada en Contestación al cuestionario económico del Gobierno. Documentación económica, $n .{ }^{\circ}$ 5, Oficina de programación y coordinación económica, Madrid, 1959.

8. GONZÁLEZ, Manuel-Jesús, La economía politica del franquismo (1940-1970), Madrid, 1979, p. 179. 
En cuanto a las ideas económicas que se propugnaban, cuatro eran fundamentales:

«El restablecimiento de la disciplina financiera merced a una política presupuestaria y monetaria de signo estabilizador.

La fijación de un tipo de cambio único y realista para la peseta.

La liberalización y globalización del comercio exterior.

Acabar con la economía recomendada, entregada al poder discrecional del Gobierno y la drogadicción de las subvenciones, las intervenciones y las concesiones para restablecer una economía mixta, basada en la flexibilidad y disciplina del mercado... ${ }^{9}$

En suma de lo que se trataba era de poner en marcha los mecanismos de mercado y romper con una larga trayectoria de nuestra política económica, en la cual el "miedo al mercado» había presidido la toma de decisiones, debido entre otras causas a la incapacidad de ciertos sectores empresariales de responder a las exigencias de la competencia de los mercados internacionales. Pero si éste fue el objetivo, hubo ciertos «frenos» que impidieron la puesta en práctica de algunos aspectos, afectando especialmente a los mercados financieros y de trabajo, y al comercio exterior.

Tras la lógica recesión ${ }^{10}$ por la entrada en vigor de las medidas estabilizadoras, a partir de 1961 se inició un importante desarrollo de la economía española. Entre 1961 y 1974 creció a un ritmo anual medio del 6,8 por ciento en términos del Producto Interior Bruto (PIB), lo que constituye una fase de crecimiento desconocida hasta entonces. Ente 1964 y 1974, el crecimiento se debió sobre todo al tirón del sector industrial -la media fue del 9,5 por ciento-, y en menor medida al de la construcción -el 6,8 por ciento-y los servicios -el 6 por ciento-. El sector agrícola creció más moderadamente -el 2,7 por ciento-, asistiéndose a una pérdida de influencia del mismo que será continua e irreversible. España completaba así su proceso de industrialización, y como afirmaba Rostow: «España (...) va cerrando el desfase con Europa occidental iniciado hace unos ciento sesenta y cinco años»11. La rapidez del proceso fue sin duda lo más llamativo.

Los cambios económicos y las transformaciones sociales favorecieron el resurgimiento de las acciones colectivas y los conflictos sociales, que se manifestaron en los sectores sociales que habían sufrido su impacto. En la iglesia, en las universidades, en la ciudad o en las fábricas y centros de trabajo, la respuesta fue el incremento del disentimiento y la protesta. Así se da la paradoja que

9. Fuentes QUiNTANA, Enrique, «El Plan de Estabilización económica de 1959, veinticinco años después", Información Comercial Española, n. ${ }^{\circ} 612-613$ (agosto-septiembre 1984), p. 35.

10. Las cifras de paro se incrementaron, así en el cuarto trimestre de 1959 había 91.000 personas en paro; y en el mismo trimestre de 1960 se elevaban a 132.000. Aunque las cifras eran bajas, la respuesta de las autoridades fue establecer en 1961 un sistema de aseguramiento general y obligatorio de las situaciones de paro forzoso mediante la Ley 62/1961, de 22 de julio, por la que se creaba el denominado Seguro de Desempleo. Véase ARANGO, Jesús, La protección por desempleo en España, Madrid, 1999, pp. 69-76.

11. Citado por CARRERAS, Albert, "España en las tipologías de la industrialización», en CARRERAS, Albert, Industrialización española: estudios de historia cuantitativa, Madrid, 1990, p. 103. 
aquellos cambios que favorecieron la mejora del nivel de vida y el bienestar de los ciudadanos, en vez de legitimar el régimen autoritario, sirvieron para potenciar la labor de la oposición.

Fueron estos actos de protesta los que más daño hicieron a la dictadura, ya que las alternativas políticas de la oposición, contaron con menos apoyos, debido a la debilidad orgánica de las organizaciones partidistas y a su persistente división.

En el campo laboral, las huelgas, pese a estar prohibidas, convivieron con la dictadura, produciéndose un significativo incremento de las mismas desde comienzos de la década de los sesenta ${ }^{12}$. Las huelgas fueron acompañadas por un aumento de las demandas presentadas en las Magistraturas de Trabajo, que dio lugar a una mejora en la posición de los trabajadores respecto a las dos décadas anteriores, debido a la ayuda de los abogados laboralistas y a una mayor sensibilidad social por parte de los jueces.

Las huelgas tuvieron las siguientes características:

1. - Nuevos protagonistas, así mientras en los años treinta eran los jornaleros sin cualificar, tanto de la construcción como del campo, los más proclives a las movilizaciones, a partir de mediados de los cincuenta son trabajadores cualificados del metal y de las industrias manufactureras. Ello no sólo responde a los cambios habidos en la estructura ocupacional, sino sobre todo al hecho de que dichos sectores se encuentran regulados por convenios colectivos, siendo la discusión de los mismos el momento en torno al cual se organizan las protestas.

2. - El tamaño de las empresas se convirtió en un factor decisivo a la hora de realizar huelgas. Así entre 1968 y 1974, el «67,4 por ciento del número total de conflictos tuvieron lugar en centros con más de 100 trabajadores (mientras que la proporción de estos centros en la economía española era del 1,3 por ciento) ${ }^{13}$. En dichas empresas se daban las condiciones para la proliferación de huelgas: existencia de un jurado de empresa que negociaba el convenio colectivo y participación en el mismo de militantes de la oposición.

3. - El marco habitual de las huelgas eran las empresas, pero con el tiempo tendieron a extenderse a la localidad donde se ubicaban, sobre todo cuando existía monocultivo industrial, como en el caso de Vigo en septiembre de 1972; a una comarca, como ocurrió en el Bajo Llobregat el 5 de diciembre de 1974; o a una región, como las habidas en el País Vasco y en Navarra los días 24 de noviembre y 11 de diciembre de 1974.

4. - - Se produjo un cambio en el tradicional mapa del conflicto, donde se combinan los rasgos definidores de las transformaciones sociales habidas en España, especialmente la industrialización y la urbanización, con la existencia de "vanguardias" organizadas con más o menos tradición. En el caso de Madrid y Guipúzcoa es indudable el peso de su intensa industrialización, y en menor

12. Véase mi artículo "Huelgas en el franquismo: casusas laborales-consecuencias políticas", Historia Social, 30 (1998), pp. 39-61.

13. MaraVall, José María, Dictadura y disentimiento politico. (Obreros y estudiantes bajo el franquismo), Madrid, 1978, p. 65. 
medida Navarra y Valladolid. Vizcaya y Barcelona, provincias con una notable presencia obrera se mantienen, mientras que Asturias se encuentra en declive.

5. - El movimiento huelguístico tuvo una importante repercusión en el exterior y la represión del mismo sirvió para concienciar a la opinión pública europea contra la dictadura franquista ${ }^{14}$.

En conclusión, los cambios introducidos con la negociación colectiva tutelada facilitaron el incremento de las huelgas y su extensión a sectores que hasta el momento habían mantenido un bajo nivel de conflictividad. La consecuencia de ello fue que la conflictividad laboral fue continua, tendiendo a hacerse permanente en las fábricas, a lo cual no era ajena la naturaleza autoritaria del régimen político.

\section{APARICIÓN Y DESARROLLO DE LA NEGOCIACIÓN COLECTIVA "TUTELADA"}

En el campo de las relaciones laborales existe un antes y un después de la publicación, en 1958, de la Ley de Convenios Colectivos Sindicales ${ }^{15}$, ya que el Fuero del Trabajo, en su redacción de 1938, no daba cabida a la negociación colectiva entre las posibles fuentes del Derecho del Trabajo ${ }^{16}$. En la Ley de Contrato de Trabajo de 1944 no se contemplaba la posibilidad de pactos colectivos:

"En las actuales circunstancias no existe en España un régimen de convenio colectivo. Previsto y regulado por la vieja Ley de 1931, ha desaparecido en la vigente de 1944... En el nuevo Estado español la organización sindical que en él priva no deja terreno hábil para una institución, como es la del pacto colectivo, que exige una sindicación horizontal, engarzada por el convenio entre entidades o representación de trabajadores y empresarios. Nuestra legislación actual ha superado el régimen de pactos colectivos de transición entre el viejo régimen liberal de contrato individual y el de la reglamentación por el Estado, entrando plenamente en la nueva vía.. ${ }^{17}$

En el modelo de relaciones laborales impuesto por el franquismo hasta 1958, primaba el papel del Estado que agrupaba a los agentes sociales en un «sindicalismo de sumisión» ${ }^{18}$ en el que se negaba la libertad, sobre todo la de los traba-

14. MATEOS, Abdón, La denuncia del sindicato vertical. Las relaciones entre España y la Organización Internacional del Trabajo (1939-1969), vol. II (1. ${ }^{2}$ Parte), Madrid, 1997, pp. 80-86.

15. Ley de 24 de abril. Fue desarrollada y completada con dos disposiciones de similar importancia: el Reglamento aprobado por la Orden Ministerial de 22 de julio, y las llamadas Normas Sindicales, dictadas por la Organización Sindical el 23 de julio, también de 1958. Dicha Ley fue sufriendo diversas modificaciones, siendo la más importante la Ley 38/1973, de 19 de diciembre, sobre Convenios Colectivos Sindicales de Trabajo, y sus normas de aplicación, aprobadas por la Orden Ministerial de 21 de enero de 1974, y la Resolución Sindical de 31 de enero de 1974

16. BORRAJO DACRUZ, Efrén, Introducción al Derecho Español del Trabajo, Madrid, 1978 (reimpresión de la cuarta edición de 1975), p. 373.

17. Garcfa Oviedo, Carlos, Tratado elemental de Derecho social, Madrid, 1946, p. 283.

18. El sindicalismo de sumisión" se "caracteriza por supeditar -o confundir- los intereses de los trabajadores a los intereses del Estado, siendo precisamente la configuración del Estado la que marca la del Sindicaton, en SAGARDOY, José Antonio, Relaciones de trabajo y estruaturas políticas, Madrid, 1984, p. 51. 
jadores, a la vez que se buscaba una "concepción armonicista de la sociedad". Aunque tras dicha concepción, lo que hubo fue capitalismo puro y duro, con los aditivos propios de un régimen autoritario y una creciente intervención del Estado, cuya máxima preocupación fue anular toda forma de protesta social.

Se estableció que "la regulación de las condiciones de trabajo corresponde al Estado ${ }^{19}$, entendiendo que las mismas fijadas por los Reglamentos de Trabajo - las Ordenanzas Laborales se consideran mínimas, mejorables a través de los reglamentos de régimen interior (que también debía aprobar la Administración), o las "relaciones individuales de trabajo». Esta situación se confirmó un año después por la Ley que establecia las normas para regular la elaboración de las Reglamentaciones de Trabajo ${ }^{20}$, en cuya Exposición de Motivos se afirmaba "que es competencia exclusiva del Ministerio de Trabajo la aprobación, aplicación e inspección de las leyes de trabajo", y a continuación se fijaba que sería "función privativa del Estado» toda regulación sistemática de las condiciones mínimas a que han de ajustarse las relaciones laborales. Por lo que asistimos al establecimiento de un modelo de relaciones laborales «unitario» ${ }^{21}$, donde el Estado goza de una posición monopolista en todo lo relativo a la fijación de las condiciones de trabajo.

La Ley de Convenios Colectivos de 1958 puso en marcha por tanto la negociación colectiva, que fue adquiriendo un notable desarrollo, llegando a afectar a más del ochenta por ciento de la población ocupada. ¿Qué fue lo que condujo a que las autoridades tomaran dicha decisión? Ésta es la pregunta clave que nos debemos hacer. Parece evidente que la misma trataba de ser una respuesta a la lógica del desarrollo capitalista, y no fue fruto de la presión del movimiento obrero, todavía muy débil y en proceso de transformación ${ }^{22}$.

Pensar que ciertas huelgas en el norte y Barcelona condicionaron, a finales de la década de los cincuenta, una decisión de tal envergadura, responde no tanto a la realidad de los hechos, sino a la denominada historiografía resistencialista, que trata de "contrapesar la posición oficial de la dictadura" ${ }^{23}$.

El cambio en el marco institucional era necesario, ya que su rigidez impedía el desarrollo de la producción, como la propia Organización Internacional del Trabajo (OIT) reconocería unos años después:

"(...) se trató de una modernización de las instituciones tendente a dar mayor flexibilidad al mercado y mayor realismo a la fijación de los salarios... provocando, al mismo tiempo, un proceso en el cual los empresarios... se verían obligados a racionalizar sus métodos de producción y a mejorar los rendimientos. Se actuaba así

19. Decreto de 29 de marzo de 1941.

20. Ley de 16 de octubre de 1942 (Boletin Oficial del Estado, de 23 de octubre).

21. FARNHAM, David y PIMLOTI, John, Understanding Industrial Relations, Londres, 1988, pp. 4-6.

22. Algunos autores piensan que la ley fue el resultado de la actuación del movimiento obrero, pues consideran un «factor fundamental la reaparición, a partir de los años 1951-53 (...), de un alto y generalizado nivel conflictual en la clase obrera», en SERRANO, Ángel y MALO DE MOLINA, José Luis, Salarios y mercados de trabajo en España, Madrid, 1979, p. 47.

23. TUSELL, Javier, «La dictadura de Franco a los cien años de su muerte» (sic), Ayer, 10, 1993, p. 21 
bajo el signo de una mayor productividad y con el objetivo de que todo aumento en el coste de la mano de obra fuera absorbido por mejoras introducidas en la estructura de la empresa y en los procedimientos de explotación. ${ }^{24}$

Pero pese a dicho cambio, seguían existiendo impedimentos para el desarrollo de una auténtica negociación colectiva, siendo el más importante la ausencia de libertad sindical. Ligado a esto último se planteó la "constitucionalidad" de la nueva norma ${ }^{25}$, resolviendo parcialmente la misma ley el tema de forma un tanto forzada. Aunque como es natural, en un Estado con Derecho, como es el franquismo, el tema de la "constitucionalidad" no era el central en la mente de los gobernantes, sino el tratar de resolver una situación, donde la legislación fundacional suponía un obstáculo al crecimiento económico, siendo este último imprescindible para la búsqueda de la «legitimidad por la eficacia» ${ }^{26}$, objetivo perseguido por los tecnócratas del Gobierno.

Un porcentaje importante de los empresarios no veía inconveniente en la nueva regulación laboral: el 33 por ciento de los mismos era favorable a la existencia de convenios colectivos, el 32 por ciento seguía estando a favor de las reglamentaciones y un 22 por ciento prefería los acuerdos individuales ${ }^{27}$. Esta opinión fue vertida a principios de 1961, lo que nos hace pensar que cuanto más se desarrolla la "negociación colectiva tutelada" más apoyo tiene.

Es sabido que el empresariado tuvo "un comportamiento adaptativo a las nuevas condiciones del entorno en el que se desenvolvió su actividad a partir de la guerra civil ${ }^{28}$, la búsqueda del máximo beneficio y la paz social se convirtieron en los ejes prioritarios de su actividad. Dichas prioridades seguían estando presentes a finales de los años cincuenta, por lo que apoyaron los cambios en la política económica, que con el tiempo se mostrarán adecuados para la obtención del primero de los objetivos, la búsqueda del máximo beneficio; pero no del segundo, ya que el nuevo marco de relaciones laborales favoreció la

24. OIT, La situación laboral y sindical en España, Ginebra, 1970, p. 201.

25. La Ley Orgánica del Estado de 1967 procedió a la modificación del Fuero del Trabajo, para dar cabida a la nueva situación. Los términos de dicha modificación, según Efrén BORRAJO, Introducción al Derecho..., p. 375, fueron básicamente dos:

1.9) La Declaración III, punto 4, establece que «El Estado fijará las bases minimas para la ordenación del trabajo...»; si las Reglamentaciones estatales ofrecen dichas condiciones mínimas, resulta obligado que su desarrollo y aplicación últimos se remitan a los pactos normativos de los grupos interesados.

$\left.2{ }^{\circ}\right)$ La nueva Declaración XIII desvincula los sindicatos del Estado, y refuerza su independencia; además, si bien el sindicato sigue siendo una corporación de derecho público, dentro de él "... se constituirán las asociaciones respectivas de empresarios, técnicos y trabajadores... para la defensa de sus intereses particulares..." (punto 3 ).

26. La legitimidad por eficacia es definida como la "capacidad de un régimen para encontrar soluciones a problemas básicos con los cuales se enfrenta todo sistema político», en LiNZ, Juan J., La quiebra de la democracia, Madrid, 1987, p. 46.

27. Linz, Juan J. y De Miguel, Amando, "Los problemas de la retribución y el rendimiento visto por los empresarios", Revista de Trabajo, 1 (1963), tabla 3.

28. TORRES VILIANUEVA, Eugenio, "Comportamientos empresariales en una economía intervenida: España, 1936-1957», en SÁNCHEZ ReCIO, Glicerio y TASCÓN FERNÁNDEZ, Julio (eds.), Los empresarios de Franco. Política y economía en España, 1936-1957, Barcelona, 2003, pp. 220 y 221. 
confrontación y con ello el incremento de la actividad huelguística. Pese a ello, el resultado fue beneficioso para los empresarios, que habitualmente contaban con la colaboración de las autoridades.

La normativa sobre convenios colectivos fue recibida de forma distinta por las organizaciones obreras de la oposición. En la Unión General de Trabajadores (UGT) existían unas marcadas diferencias entre lo que pensaba Rodolfo Llopis, que se encontraba en el exilio, y Antonio Amat. Mientras que el primero rechazaba utilizar los resquicios legales que ofrecía el régimen; el segundo, mejor conocedor del ambiente que se vivía en España, era partidario de la participación discreta de los socialistas en las elecciones sindicales. Así en las elecciones de 1954 y 1957, excepto en Asturias, militantes y cuadros de la UGT serían elegidos" ${ }^{29}$. Esta práctica no impedía que se apoyasen las "Comisiones de Fábrica» cuando ello era posible, como sucedió en Vizcaya durante 1956. En agosto de 1960, el Consejo General de la UGT aprobó una resolución, que se mantendría hasta el final de la dictadura, que establecía la no participación en las elecciones sindicales, propugnando el boicot a las mismas. A esta postura se sumarian Solidaridad de Trabajadores Vascos (STV) y la Confederación Nacional del Trabajo (CNT).

En cambio las organizaciones católicas que trabajaban en los medios obreros, como la Juventudes Obreras Católicas (JOC) y la Hermandad Obrera de Acción Católica (HOAC), decidieron participar en las elecciones sindicales, al igual que la recién creada Unión Sindical Obrera (USO). Pero sobre todo lo hicieron los comunistas ${ }^{30}$, que vista la incapacidad de la Organización Sindical Obrera (OSO), frente sindical del Partido Comunista de España (PCE), decidieron apoyar y controlar las denominadas Comisiones Obreras (CC.OO.), que se convirtió en la organización de los trabajadores más activa y representativa de la oposición en España.

El alcance de la nueva normativa sobre los convenios colectivos sindicales, estaba limitada por el carácter autoritario del régimen político, que establecía,

29. Nicolás Martínez Esturo, en Vizcaya; Francisco Román, en Málaga; Juan Gómez Egido, en Madrid; Basilio Rodríguez, en Santander;... A pesar de la resolución de agosto de 1960, miembros de la UGT se presentaron y fueron elegidos como representantes sindicales.

30. «Sólo nuestro P. ha orientado a los trabajadores en el sentido de que participasen activamente en las elecciones, presentándolas como una importante batalla revolucionaria. Las jerarquias (sic) católicas, los dirigentes socialistas y anarquistas (y en algunos casos viejos obreros, incluso camaradas, que no han superado aún su sectarismo) o no han dicho una palabra o han aconsejado la abstención electoral.", en Datos conocidos sobre los resultados de las elecciones sindicales, sin fecha (1966?), en Archivo del Partido Comunista de España (en adelante APCE), fondo Movimiento Obrero, caja 89, carpeta 4, p. 2.

La posición del PCE de trabajar en el interior de los sindicatos franquistas es de 1941: «(...) es conveniente utilizar los Sindicatos para plantear las reivindicaciones de los trabajadores, utilizando formas y métodos distintos, un lenguaje diferente en consonancia con las posibilidades que estos ofrecen, utilizando a los trabajadores menos conscientes y más atrasados, para que sean ellos los que intervengan en forma más activa en su seno", en FUNDACIÓN NACIONAL FrANCisco Franco, Documentos Inéditos para la Historia del Generalísimo Franco, t. II-2, documento n. ${ }^{\circ}$ 174, p. 170. 
en primer lugar, que las partes con capacidad para contratar eran exclusivamente los representantes legales de los trabajadores y los empresarios, que se encontraban insertos en el Sindicato Vertical; segundo, que la iniciativa para que se produjera la negociación era una competencia exclusiva de la Organización Sindical Española (OSE); y en tercer lugar, que el convenio acordado sólo era eficaz si lo aprobaba el Ministerio de Trabajo. La intervención del Estado era pues una constante. El objetivo fijado en el preámbulo y el articulado de la ley que regulaba los convenios colectivos sindicales se movía entre el recuerdo del viejo lenguaje nacional-sindicalista y el de la nueva racionalidad capitalista, así mientras hablaba de la "colaboración armónica en el campo sindical» y de «fomentar el espíritu de justicia social y el sentido de unidad de producción y comunidad de trabajo», introducía que las «normas contractuales» debían de nacer del «libre juego de las partes interesadas" y de la "elevación de la productividad", conceptos difíciles de encajar con los anteriores.

La iniciativa de la negociación se establecía a través de la obligación de comunicar a la autoridad laboral la propuesta inicial realizada por el Sindicato. Aunque a partir de $1962^{31}$ se contemplaba un nuevo sistema para iniciar la negociación, así el artículo $3 .^{\circ}$ del Decreto sobre regulación de conflictos colectivos establecía que en "una situación de conflicto colectivo, cuando no exista convenio inicial, la autoridad laboral podrá decretar inmediatamente, a instancia de cualquiera de las partes y previo intento de conciliación sindical, la constitución de la Comisión negociadora del convenio, procediéndose seguidamente en la forma prevista en la Ley de Convenios». Esta nueva fórmula fue de nuevo contemplada en otro Decreto de $1970^{32}$.

Durante la negociación, la intervención del Estado estaba permanentemente presente, como hemos visto, ya que para que un convenio tuviera eficacia jurídica era imprescindible que fuese aprobado por la autoridad laboral, ya fuese el Delegado Provincial de Trabajo o el Director General de Trabajo en el caso de los convenios interprovinciales. Por último, la intervención más contundente, que anulaba la libertad de las partes, era sin duda la capacidad por parte del Ministerio de Trabajo de dictar normas de obligado cumplimiento, en el caso de que los empresarios y trabajadores no llegasen a un acuerdo, o no coincidiesen con el criterio de la autoridad laboral.

A ello hay que sumar dos características más: la negociación se hacía en el seno del sindicato vertical y las huelgas estaban prohibidas. Ahora bien, ambas características suponen un obstáculo a la propia negociación y una rémora para la parte obrera. No obstante, la decisión de parte de la oposición de participar en las elecciones sindicales, implicó un fortalecimiento de la misma y una quiebra del modelo de relaciones laborales, ya que ocupó los escalones representativos del sindicato y, a la vez, procedió a la movilización. Ambas decisiones

31. Como consecuencia de la aprobación del Decreto de 20 de septiembre de 1962 sobre la regulación de conflictos colectivos.

32. Decreto de 22 de mayo de 1970. 
se movían en una dialéctica de legalidad-ilegalidad. El Estado siempre estuvo a la defensiva, mientras que la oposición fue adquiriendo un poder real, que condujo a algunos empresarios a reconocer a los representantes legítimos de los trabajadores, estuvieran o no al margen de la legalidad desbordada.

A partir de la inexistencia de libertad sindical y de la presencia permanente y compulsiva del Estado, es importante conocer cómo se veía la utilización de la negociación desde la perspectiva obrera. En este sentido la estrategia diseñada por el PCE es la que va a definir mejor lo sucedido desde comienzos de la década de 1960. Para dicho partido:

"Conviene tener claridad sobre lo que hemos de entender por LUCHA y MEDIOS DE LUCHA de los trabajadores. En este terreno hemos de huir de toda concepción maximalista y exclusiva. No hemos de ver acciones de lucha solamente en las huelgas, solemente (sic) en los grandes plantes y otras acciones espectaculares. Más aún; no será posible llegar a estas elevadas formas de lucha si no pasamos previamente por una etapa en la que, de forma parcial, ejerciendo la presión por medio de simples peticiones e incluso solamente de consultas, por medio de acciones limitadas, se desarrolle el sentido de unidad de los trabajadores, se perfile un programa, se adquiera el hábito de reclamar, se pierda el miedo al camino de la dirección de la empresa, de las oficinas de los ingenieros, de los locales de los sindicatos. ${ }^{33}$

Para llevar a cabo esta estrategia era imprescindible ser elegido enlace sindical - vocal de jurado de empresa, por lo que las elecciones sindicales se presentaban como un momento fundamental en el desarrollo de la "lucha obrera", pues el ser elegido garantizaba el protagonismo entre los trabajadores, la posibilidad de obtener ventajas laborales para el colectivo representado y el liderazgo social y político ${ }^{34}$.

Por tanto, los jurados de empresa, como órgano de representación, se convirtieron en un lugar fundamental para la defensa de los intereses de los trabajadores. La normativa establecía que tenían derecho a la elección de jurado todas las empresas con más de cincuenta trabajadores. Quedaban excluidas las plantillas de menos de esta cifra que elegían a los enlaces sindicales. Los vocales del jurado eran elegidos entre los enlaces sindicales que conseguían un mayor número de votos.

Tras los enlaces y los vocales, las diversas Secciones o Juntas Sociales -más tarde denominadas Uniones de Trabajadores o técnicos- se convertían en el objetivo a ocupar. En conclusión, con la normativa sobre convenios colectivos, el jurado de empresa adquiría un contenido reivindicativo y negociador, pasando a ser un lugar de confrontación y en escasa medida de colaboración. El obrero elegido se convertía en el representante de los trabajadores frente a la empresa.

33. Sobre la cuestión de la Oposición Sindical Obrera, Madrid, diciembre 1963, en APCE, fondo Movimiento Obrero, caja 89, carpeta 4, p. 1.

34. Sirva de ejemplo el caso de Paco Cabral (líder campesino en el Marco de Jerez) "que fue presidente de la "sección social" del Sindicato Vertical durante veinticinco años, desde 1952", ingresando en 1968 en el PCE, en FoWeraKer, Joe, La Democracia Española, Madrid, 1990, p. 48. 
En los primeros años de su aplicación, la Ley de Convenios Colectivos tuvo escasa difusión debido a «la puesta en marcha de las medidas estabililizadoras » ${ }^{35}$, de hecho entre 1958 y 1961 hubo tan sólo 829 convenios, que afectaron a algo más de un millón y medio de trabajadores. El primer convenio firmado fue el de Astilleros del Cantábrico, en Asturias.

Tras la coyuntura estabilizadora se produjo el comienzo de una fuerte reactivación económica, que fue acompañado de un importante incremento en el número de convenios, así como del aumento de la conflictividad laboral.

\section{Tabla 1. Evolución de los convenios y normas de obligado cumplimientos aprobados en el período (1958-1975)}

\begin{tabular}{|c|c|c|c|c|c|c|}
\hline \multirow{2}{*}{ AÑOS } & \multicolumn{2}{|c|}{ CONVENIOS } & N.O.C. Y LAUDOS (1) & \multicolumn{2}{|c|}{ TOTAL } \\
\cline { 2 - 7 } & Número & $\begin{array}{c}\text { Trabajadores } \\
\text { afectados }\end{array}$ & Número & $\begin{array}{c}\text { Trabajadores } \\
\text { afectados }\end{array}$ & Número & $\begin{array}{c}\text { Trabajadores } \\
\text { afectados }\end{array}$ \\
\hline 1958 & 7 & 18.547 & - & - & 7 & 18.547 \\
\hline 1959 & 205 & 433.229 & - & - & 205 & 433.229 \\
\hline 1960 & 168 & 322.871 & 1 & 350 & 169 & 323.221 \\
\hline 1961 & 449 & 937.316 & - & - & 449 & 937.316 \\
\hline 1962 & 1.538 & 2.316 .413 & 41 & 103.162 & 1.579 & 2.419 .575 \\
\hline 1963 & 1.027 & 1.822 .374 & 56 & 71.900 & 1.083 & 1.894 .274 \\
\hline 1964 & 994 & 1.419 .020 & 113 & 369.466 & 1.107 & 1.788 .486 \\
\hline 1965 & 1.147 & 1.905 .221 & 182 & 583.253 & 1.329 & 2.488 .474 \\
\hline 1966 & 937 & 1.733 .860 & 132 & 432.103 & 1.069 & 2.165 .963 \\
\hline 1967 & 1.055 & 1.625 .151 & 186 & 507.881 & 1.241 & 2.133 .032 \\
\hline 1968 & 165 & 315.952 & 11 & 71.764 & 176 & 387.716 \\
\hline 1969 & 1.578 & 3.765 .896 & 181 & 516.958 & 1.759 & 4.282 .854 \\
\hline 1970 & 1.673 & 4.178 .495 & 156 & 357.722 & 1.829 & 4.531 .217 \\
\hline 1971 & 1.184 & 2.105 .687 & 135 & 156.360 & 1.319 & 2.262 .047 \\
\hline 1972 & 1.560 & 4.026 .206 & 205 & 482.922 & 1.765 & 4.509 .128 \\
\hline 1973 & 1.422 & 2.962 .942 & 149 & 328.243 & 1.571 & 3.291 .185 \\
\hline 1974 & 1.634 & 2.224 .696 & 122 & 793.111 & 1.756 & 4.017 .807 \\
\hline 1975 & 1.027 & 1.818 .788 & 189 & 915.419 & 1.216 & 2.734 .207 \\
\hline
\end{tabular}

Elaboración propia. Nota: (1) Normas de Obligado Cumplimiento. Desde 1973, Decisiones Arbitrales Obligatorias. Fuente: ORGANIZACIÓN SindiCAL (Oficina Central de Convenios Colectivos), Convenios Colectivos Vigentes, años respectivos.

Hasta 1965, el número de los primeros convenios superaba al de las revisiones, pero en dicho año frente a 167 "primeros", se aprobaron 888 revisiones. Entre 1958 y 1967, el 37 por ciento de los convenios fueron de ámbito provincial,

35. Organización SindiCal (Oficina Central de Convenios Colectivos), Estadisticas de Convenios Colectivos de Trabajo 1958-1967, Madrid, 1968, p. 18. 
con algo más del 70 por ciento de las empresas y casi el 60 por ciento de la población total trabajadora, a continuación, si tomamos como criterio el número de trabajadores afectados, se situaban los convenios de ámbito interprovincial, y por último, los referidos a las empresas.

La distribución geográfica en este período muestra un desfase entre el número de los convenios y la población ocupada. Es cierto que Madrid, Barcelona y Valencia sobrepasaban el 35 por ciento de los mismos y el 41 por ciento de los trabajadores afectados. Pero en el caso de Valencia obedecía al enorme número de convenios agrícolas, al igual que ocurría con Málaga o Salamanca. De hecho la atomización de las actividades agrícolas producía un número muy elevado de convenios, que no se correspondían con el número de trabajadores afectados. Éste fue el caso de Orense y Soria, donde había 29 convenios para algo más de dieciocho mil trabajadores.

Sectorialmente, entre 1958 y 1967, fue la Hermandad Sindical de Labradores, la que negoció más convenios que además afectaban al mayor número de trabajadores. Este dato no se ha tenido en cuenta habitualmente, ya que la imagen de la rápida industrialización que se estaba llevando a cabo, se trasladaba a la negociación colectiva de forma mimética, cuando la realidad era bien distinta.

A continuación se situaba el Sindicato del Metal, con algo más de un millar de convenios que afectaban al 14 por ciento de las empresas y al 19 por ciento de los trabajadores. Ahora bien, la importancia del metal se visualizaba, no sólo por ser un sector en plena expansión, a diferencia de la agricultura, sino por la fuerte conflictividad que generaba, ya que en él se encontraban las vanguardias más activas de la oposición obrera. Por ello, fue en el metal donde se aplicaron con mayor frecuencia las normas de obligado cumplimiento, dada la dificultad de llegar a acuerdos entre las partes.

Otros sindicatos que presentaban un peso considerable fueron los de la construcción, vidrio y cerámica, que sobrepasaban el millón de trabajadores con convenios, seguidos de cerca por el textil.

La consecuencia más importante, desde el punto de vista económico, de la negociación colectiva hasta 1967 fue la modificación de la rígida estructura del sistema salarial ${ }^{36}$. La negociación colectiva se centró en temas salariales, con especial incidencia en las retribuciones pactadas en función de los rendimientos. Se avanzó de forma importante en el incremento de la productividad, así como en la introducción de maquinaria, lo que permitió la reducción del tiempo de trabajo, mientras aumentaba la producción y se creaban pocos puestos de trabajo. Por ello, la consideración más sobresaliente fue mejorar la competitividad, renovando el capital fijo, sin tener en cuenta la existencia del abundante factor de producción trabajo, que debido a la emigración y al alza generalizada del nivel de vida, tenía una capacidad limitada de presión desde una perspectiva económica, aunque no política.

36. Un estudio pormenorizado sobre dichas modificaciones en SERRANO, Ángel y MALO DE MOLINA, José Luis, Salarios y mercados..., op. cit., pp. 85-140. 
Desde 1967 y hasta 1975, la dinámica de la negociación colectiva sufrió ciertas variaciones en un marco socio-político cada vez más complicado por tres razones. La primera de ellas fue la decisión del Tribunal Supremo de ilegalizar a CC.OO., dada su vinculación al PCE ${ }^{37}$. Dicha medida no sirvió, junto a otras de tipo represivo (declaración de sucesivos estados de excepción, sanciones contra enlaces y jurados,...), para frenar el fortalecimiento de CC.OO. y el incremento de su representatividad. La segunda razón tiene que ver con las cada vez más visibles diferencias entre la clase política del franquismo, la cual responde de forma contradictoria a las demandas obreras. La tercera es que se producen los primeros síntomas de una grave crisis económica, siendo incapaz el Gobierno, de hacerle frente debido a la parálisis política originada por la cercana desaparición del dictador. Fortaleza de la oposición, desconcierto y proyectos distintos de los franquistas plantean una situación de crisis.

Si estudiamos la negociación colectiva, tomando como muestra $1973^{38}$, se puede apreciar que dicho año junto al anterior fueron muy positivos desde el punto de vista de la actividad económica, aunque en este último comenzaba a preocupar la tendencia alcista de los precios. Aunque se redujo el volumen de convenios suscritos y el número de trabajadores afectados, las cantidades seguían siendo importantes, ya que no será hasta 1975 , cuando se note un significativo descenso. Las normas de obligado cumplimiento afectaron al 10 por ciento de los trabajadores.

Los convenios de rama fueron más numerosos que los de empresa ${ }^{39}$. Los sectores con mayor volumen de población protegida por convenio fueron el metal, construcción, agrario, hostelería y banca; y las provincias que encabezaban la población con convenio seguían siendo Barcelona, Madrid y Valencia. Los in-

37. Es interesante el informe realizado por Ignacio Morilla (procurador en Cortes) en el que afirma: "la necesidad de que se conozca en toda su realidad las actividades de las "Comisiones Obreras" y destaca su peligrosidad, no solamente en el campo laboral, sino tambien (sic) en el terreno político, ya que dado su matiz y dependencia comunista, sus actividades en lo laboral es simple escalón para alcanzar objetivos más trascendentales, cuales son la invasión de la propia extructura (sic) sindical española y el derrocamiento del Régimen vigente.», en Informe sobre las llamadas Comisiones Obreras, mayo 1967, en APCE, fondo Movimiento Obrero, caja 87, carpeta 1, p. 1.

38. Los datos provienen de los siguientes informes: ORGANIZACIÓn SindiCAL (Oficina Central de Convenios Colectivos), Convenios Colectivos Sindicales. Información interna para los órganos sindicales destinatarios (Primer Trimestre), 1, 1973; ORGANIZACIÓN SindICAL (Oficina Central de Convenios Colectivos), Convenios Colectivos Sindicales. Información interna para los órganos sindicales destinatarios (Segundo Trimestre), 2, 1973; ORGANIZACIÓN SindiCAL (Oficina Central de Convenios Colectivos), Convenios Colectivos Sindicales. Información interna para los órganos sindicales destinatarios (Tercer Trimestre), 3, 1973; y, ORGanIZACIón SindICAL (Oficina Central de Convenios Colectivos), Convenios Colectivos Sindicales. Información interna para los órganos sindicales destinatarios (Cuarto Trimestre), 4, 1973.

39. Mientras que los convenios de rama engloban los convenios de ámbito interprovincial de rama, provincial, comarcal y local, los convenios de empresa engloban los convenios de ámbito interprovincial de empresa, grupo de empresa y empresa. 
formes constatan que se estaba llegando al nivel de saturación del sistema, ya que el porcentaje de trabajadores con convenio suponía el 87,1 por ciento ${ }^{40}$.

Tal vez el dato más interesante, junto al del nivel de saturación, era que juntos a los aspectos salariales que se incluían en el cien por cien de los convenios, se iban introduciendo en los mismos otros temas de carácter asistencial, formativo y de promoción social, por lo que se asistía a una mayor diversificación temática en la negociación y a un enriquecimiento de la misma.

Las normas de obligado cumplimiento o arbitrales obligatorias afectaron como media entre 1960 y 1975 , al 13,5 por ciento de los trabajadores con convenio, habiendo dos períodos por encima de la media: 1964-68 y 1974-75. En concreto en este último se dio el mayor porcentaje ya que el 33,5 por ciento de los trabajadores que firmaron convenio se vieron sometidos a un laudo. La curva de huelgas y de normas de obligado cumplimiento presentan un perfil similar, lo que pone de manifiesto la relación entre negociación colectiva y conflictividad laboral.

\section{AUSENCIA DE LIBERTAD SINDICAL Y NEGOCIACIÓN COLECTIVA}

El modelo sindical impuesto por el franquismo tuvo los siguientes rasgos característicos: $10^{\circ}$ - La sindicación se declaraba obligatoria, aunque no formalmente ${ }^{41}$. En la práctica se producía la sindicación automática por el hecho de poseer la condición de empresario o trabajador; $2 .^{\circ}-$ Se proclamaba el principio de unidad en un mismo sindicato de empresarios y trabajadores y se rechazaba el pluralismo sindical. Con ello se pretendía recuperar la armonía entre los hombres y al ser el Sindicato una "unidad natural de convivencia», patronos y obreros debían participar conjuntamente, siendo la sindicación vertical el marco adecuado, ya que superaba la lucha de clases; $3 .^{\circ}-$ El sindicato se constituía como una entidad de derecho público; y $4 .{ }^{\circ}$ - El Sindicato no tenía capacidad para realizar presión a través de la huelga, ya que estaba prohibida.

Estas características fueron más teóricas que reales, ya que hubo colectivos de trabajadores que se mantuvieron al margen del Sindicato, como fue el caso de las profesiones liberales o los funcionarios públicos, y subsistieron ciertos organismos de representación económica y profesional como las Cámaras Oficiales de Comercio, Industria y Navegación, o las Cámaras de Sindicación Agraria. Buena muestra de ello fue que en 1949, tan sólo el 48,4 por ciento de los trabajadores

40. ORGanización Sindical (Oficina Central de Convenios Colectivos), Convenios Colectivos..., 4, 1973 , p. 14.

41. De hecho hubo discrepancias sobre el tema: «El día muy próximo en que aparezca la Ley o Decreto en que se ordene la sindicación forzosa de todos los españoles, habremos echado sobre nuestras espaldas la responsabilidad más grave y más tremenda que ha contraído jamás la Falange...", en "Discurso de Gerardo Salvador Merino, pronunciado el 20 de junio de 1941 en la clausura del II Congreso Sindicaln, Boletín Sindical de la CNS, 12 (julio-agosto-septiembre), 1941. 
estaban afiliados ${ }^{42}$, y las autoridades sindicales mostraron de forma reiterada las dificultades que tuvieron para su construcción ${ }^{43}$.

Cuando José Solís se hizo cargo del Sindicato, comenzaron a plantearse cambios importantes en el mismo en línea con una mayor "apertura» ${ }^{44}$ y con el objetivo de:

«(...) excluir la demagogia social antigua, concertar pacíficamente a obreros y empresarios, democratizar por dentro al propio sindicalismo sin perder las ataduras con su propio mando, promover representantes expertos para las tareas legisladoras de Cortes, permanecer incontaminados de la política de enfrentamientos y contribuir a las grandes reformas económicas, sociales y tecnológicas del país...».45

La posición política de José Solís se fue reforzando, por lo que al calor de la «apertura» de la década de los sesenta trató de dotar al Sindicato de un mayor poder y autonomía frente al Gobierno. Para ello preparó el proyecto de Ley Sindical, que necesitaba para su puesta en práctica de algo que hasta el momento carecía la organización: representatividad.

Pero ambas cuestiones planteaban problemas, ya que la búsqueda de un mayor poder para el Sindicato entraba en conflicto con los intereses de los tecnócratas, y una mayor representatividad implicaba una mayor presencia de los miembros de CC.OO. en los escalones representativos del Sindicato.

Respecto a lo primero, tanto Laureano López Rodó como Luis Carrero Blanco expresaron en innumerables ocasiones el peligro que implicaba el proyecto de Ley avalado por Solís: «De prosperar ese proyecto -le dije (se dirige a Franco)- sólo podría gobernar en España quien tuviera en sus manos la Organización Sindical: es el único grupo, en las Cortes, en el Consejo Nacional y en el Consejo del Reino, que obedece a una disciplina política.» ${ }^{46}$. En el mismo sentido se manifiesta Carrero Blanco al comunicarle a Franco:

«La Organización Sindical, o más exactamente los altos cargos de la misma, todos ellos de libre designación, pretenden de hecho el asalto del poder. Mientras la ponencia discute y se debate prácticamente ante un muro infranqueable, la prensa del Movimiento y la prensa sindical, que, lógicamente, deben ser totalmente obedientes al Ministro Secretario General que es de quien dependen por la duplicidad de sus cargos, están constantemente azuzando al Gobierno a que envíe a las Cortes

42. BABIANO, José, Paternalismo industrial y disciplina fabril en España (1938-1958), Madrid, 1998, p. 61.

43. SANZ ORRIo, Fermín, Discurso presentado en el acto de clausura del III Consejo Asesor de Obras Sindicales, Madrid, 1950, pp. 10 y 11.

44. SÁNCHEZ, Rosario y NICOLÁS, M. ${ }^{a}$ Encarna, "Sindicalismo vertical franquista: la institucionalización de una antinomia", en Rurz, David (dir), Historia de Comisiones Obreras (1958-1988), Madrid, 1993, p. 3.

45. Romero, Emilio, Tragicomedia de España (Unas Memorias sin contemplaciones), Barcelona, 1985, pp. 92 y 93.

46. López Rodó, Laureano, Memorias: años decisivos, vol. II, Barcelona, 1991, p. 387. 
la ley por ellos propuesta. No hay día en que no surja la conminación, cada vez más insolente, al Gobierno para que remita la Ley a Cortes." ${ }^{47}$

Dicho conflicto terminará con la salida de Solís del Gobierno en octubre de 1969. La posterior aprobación de la Ley Sindical no afectará a la situación heredada, ya que el nuevo responsable de la OSE no tenía el mismo poder político que Solís, por lo que dada la naturaleza del régimen político, lo importante no era la letra de la ley sino sus apoyos. En conclusión la OSE no se movió de «su lugar» ${ }^{48}$.

Por lo que respecta a lo segundo, la representatividad, el tema fue especialmente complejo, dado que para que la misma fuera real era imprescindible la presencia de la oposición sindical, que se encontraba prohibida y fuera de los límites políticos aceptados por la dictadura.

La falta de representatividad del Sindicato había sido denunciada de forma reiterada desde la oposición, la Iglesia ${ }^{49}$ y la OIT $^{50}$. De hecho el propio Solís era consciente de dicha carencia, por lo que trató de negociar con Marcelino Camacho la integración de "comisiones obreras" en el Sindicato ${ }^{51}$, cosa que no consiguió, aunque tuvo mejor suerte con un grupo de "cenetistas»"

La representatividad se medía a través de las elecciones sindicales, que desde 1944 y con numerosos altibajos se venían celebrando. Tanto las organizaciones católicas como los comunistas decidieron utilizar dicha vía por «el carácter utilitario (...) que podían ofrecer dichas estructuras $\aleph^{53}$, hecho que se confirmó en las elecciones de 1950 sobre todo en Cataluña ${ }^{54}$, y que sirvió para impulsar las movilizaciones habidas en torno al boicot de los tranvías de 1951.

Con la ley de convenios colectivos sindicales, las elecciones adquirían una mayor importancia, ya que los enlaces sindicales y los vocales de los jurados de

47. Memorándum de Carrero Blanco a Franco titulado: Consideraciones sobre la situación politica, con fecha de 7 de mayo de 1969, recogido en Ibidem, p. 423. (El subrayado es nuestro).

48. Martínez CuAdrado, Miguel, Anuario Político Español 1970, Madrid, 1971, p. 697.

49. Existen numerosos ejemplos pero basta mencionar: $1 .^{\circ}$ - Declaración del Episcopado español sobre los principios de la doctrina social de la Iglesia que deben de informar el "futuro sindicalismo", 25 de julio de 1968; 2. .- "Declaraciones de Monseñor Montero a El Noticiero de Zaragoza", reproducido por el Boletin Oficial del Arzobispado, año CVIIl, n. 11 (noviembre 1969), pp. 717 y ss.; y $3 .^{\circ}$ - Declaración de los Consiliarios de Vanguardias Obretas, Madrid, 9 de enero de 1969, en Fondo María Luisa Suárez (Archivo Histórico de Comisiones Obreras-Fundación $1^{\circ}$ de Mayo) (en adelante AHCO-FPM), carpeta $67-15$, p. 2.

50. Punto 1.244 del «Informe OIT", en España Perspectiva, 1970, Madrid, 1970, pp. 342 y 343. Un análisis pormenorizado sobre el Informe de la OIT en MARTínEz QUINTEIRO, Esther, La denuncia del sindicato vertical. Las relaciones entre España y la Organización Internacional del Trabajo (19691975), vol. II (2. a parte), Madrid, 1997, pp. 37-181.

51. CAMACHO, Marcelino, Confieso que he luchado. Memorias, Madrid, 1990, pp. 176-179.

52. BULNES, Ramón, "Del sindicalismo de represión al sindicalismo de integración", Horizonte español 1966, II, París, 1966, pp. 285-325; y Ramos, Carlos, "«El Cincopuntismo en la CNT", 1965-1966. (Investigación sobre el proceso de discusión mantenida entre un grupo de militantes libertarios y representantes del Sindicato Vertical. Abril 1965-abril 1966)", en TUSELL, Javier y otros, La oposición al Régimen de Franco, t. 1, vol. 2, Madrid, 1990, pp. 137-155.

53. SARTORIUS, Nicolás, El resurgir del movimiento obrero, Barcelona, 1975, p. 25.

54. LUDEVID, Manuel, El movimiento obrero en Cataluña bajo el franquismo, Barcelona, 1977, p. 11. 
empresa se convertían en agentes negociadores de las condiciones de trabajo, y por tanto en protagonistas centrales de la lucha obrera.

En junio de 1966, Solís anunció que se estaba llevando a cabo un estudio previo para una futura Ley Sindical en la que todos aquellos que tuviesen cualquier nivel de representatividad podrían participar ${ }^{55}$. Este llamamiento coincidía con las elecciones sindicales que se estaban llevando a cabo y en las que se había realizado, por parte de las autoridades, un enorme esfuerzo para que los trabajadores participasen en las mismas. Bajo el lema «Vota al mejor», la participación alcanzó, según la OSE, el 83,3 por ciento.

La participación de simpatizantes y militantes de CC.OO. fue notable, aunque es difícil saber con precisión el número de enlaces sindicales y vocales de jurados de empresa pertenecientes a dicha organización.

Un informe «rigurosamente confidencial» y destinado «exclusivamente a los miembros del CC» (se refiere al Comité Central del PCE) nos da numerosos datos por provincias y empresas que permiten hacerse una idea de los miembros de CC.OO. elegidos, pero no sirve para hacer un cuadro estadístico ${ }^{56}$. Del mismo se desprende la importante presencia de miembros del PCE y de simpatizantes en las candidaturas de CC.OO.

Las elecciones de 1971 estuvieron marcadas por el debate en torno a la conveniencia o no de participar en las mismas. Ello provocó un incremento de la abstención, sobre todo en algunas provincias como Vizcaya. Así en empresas tan importantes como Westinghouse, Euskalduna, la Naval o Firestone la participación apenas superó el 20 por ciento ${ }^{57}$, pero se produjo un hecho un tanto sorprendente, la participación fue mayor en las medianas y pequeñas empresas de la provincia, ya que en las mismas los representantes sindicales hacían una labor importante y constructiva a favor de los trabajadores.

En cambio, en Cataluña la participación fue elevada, aunque no tanto como en las anteriores elecciones, y el triunfo de las "candidaturas obreras" fue «notable» ${ }^{58}$. Por último, en Madrid también se produjo un descenso en la participación, ya que dentro de CC.OO. algunos sectores vinculados a la extrema izquierda defendieron el «boicot». A pesar de ello, la dirección de CC.OO., prácticamente monopolizada por el PCE, afirmó que dichas elecciones significaron «un importante paso adelante» ${ }^{59}$.

55. «Declaraciones de José Solís", Solidaridad Nacional, 6 de junio de 1966.

56. Datos conocidos sobre los resultados de las elecciones sindicales, sin fecha (1966?), en APCE, fondo Movimiento Obrero, caja 89, carpeta 4, pp. 1-12.

57. IbARRA, Pedro, El movimiento obrero en Vizcaya: 1967-1977. Ideología, organización y conflictividad, Bilbao, 1987, pp. 188-191. Para José A. PÉREZ, la media de participación fue un 26,8 por ciento, y en la margen izquierda, que concentraba la mayor parte de las empresas y trabajadores, el índice apenas llegó al 19,2 por ciento, en Los años del acero. La transformación del mundo laboral en el área industrial del Gran Bilbao [1958-1977]. Trabajadores, convenios y conflictos, Madrid, 2001, p. 347.

58. RIeRA, Ignasi y Botella, José, El Baix Llobregat. 15 años de luchas obreras, Barcelona, 1976, pp. 79-80.

59. CASAS, José I. y otros, Getafe. Lucha obrera bajo el franquismo, Madrid, 1977, p. 61. 
En cambio, las elecciones sindicales de 1975 van a suponer un rotundo éxito de las Candidaturas Unitarias y Democráticas (CUDs) formadas básicamente por miembros de USO y CC.OO. Estas últimas se fijaron como objetivo "ganar las Elecciones en todos los centros de trabajo ${ }^{60}$, para ello elaboraron un programa en el que junto a las demandas netamente laborales, se incluían la petición del derecho de reunión y huelga, la libertad sindical, la readmisión de los despedidos y la amnistía.

La participación según la OSE superó el 88 por ciento, y el triunfo de las CUDs fue evidente aunque el Servicio de Información de la Organización Sindical trató de minimizarlas ${ }^{61}$, los resultados conocidos desmienten tal afirmación. Cerca del 40 por ciento de los representantes elegidos fueron de CC.OO. y otro 40 por ciento eran simpatizantes o se encontraban encuadrados en las CUDs $^{62}$.

En la región valenciana triunfaron en la primera vuelta «las CUDs en todas las grandes y medianas empresas del metal, madera, banca, vidrio y cerámica, transporte, piel y calzado, hospitales, textil, químicas, artes gtáficas.... ${ }^{63}$. En el País Vasco las cifras de participación superan el 80 por ciento en Vizcaya ${ }^{64}$ y en la mayoría de los centros de trabajo triunfaron las CDUs, pese a la división existente en CC.OO. y a la implantación en dicha región de la UGT y ELA-STV que estaban a favor del "boicot». Los datos de Guipúzcoa ${ }^{65}$ confirman lo anterior de forma muy concreta. Existen empresas donde triunfó el boicot (NIESSEN-Rentería-, Koipe -San Sebastián-, Voith-Tolosa-, CAF-Gohierri-,...) y en otras votaron la mayor parte de la plantilla (CAF-Irún-, Papelera-Rentería-, Suchard -San Sebastián-, Bianchi-Oria-, Michelin -Lasarte-, Orbegozo-Hernani-,...).

En Barcelona, el éxito fue mury significativo en las grandes empresas (SEAT, Roca, Siemens, Olivetti, Gallina Blanca,...), donde las CUDs obtuvieron en torno al 78 por ciento de los votos emitidos. Lo mismo ocurrió en Madrid (Credit Lyonnais, Televisión, ENASA, Kelvinator, CASA, Marconi,... $)^{66}$, donde se puede hablar de "una victoria rotunda de las candidaturas unitarias y democráticas" ${ }^{67}$.

Aunque existen algunos casos anteriores, la infiltración en los segundo niveles de representación sindical había sido excepcional, no sólo por las trabas que imponía el sistema electoral, sino también por la utilización de las diversas

60. Declaración de la Coordinadora General de Comisiones Obreras, abril de 1975.

61. CuE, Gloria, "Las elecciones sindicales de 1975 en la historia del sindicalismo de posguerra", Revista de Estudios Sindicales, 41, p. 39.

62. HAMANN, Kerstin, "Afiliación, movilizaciones y aliados políticos: las incógnitas del poder sindical español (1970-1988)", Cuadernos de Relaciones Laborales, 3 (1993), p. 117.

63. BENEYTO, Pere y PICó, Josep, Los Sindicatos en el País Valenciano (1975-1981), Valencia, 1982, p. 15.

64. PÉrez, José A., Los años del acero..., p. 377.

65. Resultados de las elecciones sindicales en Guipúzcoa, Guipúzcoa, 22 de junio de 1975, en APCE, fondo Movimiento Obrero, caja 91, carpeta 4, pp. 1-6.

66. Datos en GDS, anexo al número $48-49$ (mayo-junio 1985), pp. 123-124.

67. DíAz CARDIEL, Víctor, y otros, Madrid en huelga: enero 1976, Madrid, 1976, p. 70. 
formas de represión para impedirlo. Pese a ello se asistió a un significativo éxito también en los segundos niveles:

«De acuerdo con la Organización Sindical, sólo el 14 por 100 de los presidentes de agrupación fueron reelegidos, por lo que la renovación alcanzaría al 86 por 100. Los porcentajes de puestos obtenidos por las candidaturas democráticas van de $60 \mathrm{al}$ 100 por 100 en los sectores más importantes: Metro: 8 de 12; Electricidad: 29 de 29; Editoriales: 30 de 30; Hospitales: 19 de 21; Telefónica: 7 de 13." ${ }^{68}$

Pese a las garantías que establecía la legislación sindical a los representantes elegidos por los trabajadores, la realidad fue que cuando las autoridades consideraron necesario hacer uso de la represión lo hicieron, utilizando la «extinción del contrato» como fórmula habitual de acabar con los "díscolos». El ser representante de los trabajadores y mantener una actitud reivindicativa, sin duda, se convirtió en una opción de riesgo. En febrero de 1966 trabajadores metalúrgicos de Madrid denunciaban que el ser representante sindical suponía desde «la postergación profesional, pasando por la congelación de sus salarios, siguiendo por la sanción y el despido, cuando no la detención» ${ }^{69}$. Cuando esta última se producía, la empresa procedía al despido del trabajador por inasistencia al trabajo.

Existen otros casos como el de una enlace sindical que denunció a su empresa porque la dirección de la misma desde que fue elegida decidió cambiarle su puesto de trabajo, lo cual representó pérdida de salario y no tener contacto con los que la eligieron ${ }^{70}$. El traslado fue otra de las tácticas utilizadas, incluso antes de ser elegido como le ocurrió a un trabajador de Telefónica ${ }^{71}$, o la existencia de trato vejatorio al enlace elegido ${ }^{72}$.

También se utilizó la suspensión de funciones y el despido. Así ocurrió con Marcelino Camacho al que en primer lugar se le rebajó de categoría pro-

68. CUE, Gloria, «Las elecciones...», p. 41.

69. COMISIÓN DE ENLACES Y JURADOS DE EMPRESA Y TRABAJADORES METALÚRgICOS MADRILEÑos, "Carta al Excmo. Delegado Nacional de Sindicatos", Madrid, 22 de febrero de 1966, en APCE, fondo Movimiento Obrero, caja 88 , carpeta 78/81, p. 1. En dicha página también se afirma: "Mientras tanto, decenas y decenas de estos hombres conocen estarilidad (sic) de tales súplicas. Ayer, siete de ellos arrojados a la calle en Pegaso; en Schneider otros dos están sin trabajo desde 1962; de la Unión Española de Explosivos; de la Compañía Anónima Vers; de la E.M.T.; de Renfe; de Barreiros; de C.A.S.A.; de M.M.M.... pocas son las empresas que no tienen uno o varios perseguidos o despedidos.n

70. «Expediente de denuncia a la Delegación de Trabajo sobre derechos sindicales de una trabajadora contra la empresa Barburo, s.a. (Sector Químicas)», en Fondo María Luisa Suárez (AHCOFPM), 27 de mayo de 1972, carpeta 19-28.

71. "Expediente de infracción de la ley de elecciones sindicales por coacciones de un trabajador contra la empresa Compañía Telefónica Nacional de España (Sector Comunicaciones)», en Fondo María Luisa Suárez (AHCO-FPM), 15 de junio de 1975, carpeta 16-7.

72. "Expediente de denuncia a la Delegación de Trabajo sobre categoría profesional y derechos sindicales de un trabajador contra la empresa Unvisa, s.a. (Sector Vidrio)», en Fondo María Luisa Suárez (AHCO-FPM), 18 de abril de 1973, carpeta 23-24. 
fesional ${ }^{73}$ y posteriormente se le suspendió de funciones ${ }^{74}$; situación que se repitió con otros miembros del Jurado de Empresa, como Julián Ariza, hasta variar por completo la fisonomía del Jurado. De hecho desde enero de 1967, los empresarios tuvieron las manos libres para despedir a los enlaces sindicales, ya que una sentencia del Tribunal Supremo estableció la posibilidad de no admisión de los enlaces sindicales despedidos a cambio del pago de una indemnización.

Entre septiembre de 1966 y marzo de 1968 fueron desposeídos de sus cargos sindicales 127 representantes ${ }^{75}$ de los cuales 38 eran de fábricas ubicadas en Cataluña ${ }^{76}$. Desde 1969 la represión fue en aumento y era frecuente la detención de los cargos sindicales cuando se producía una huelga en la fábrica que los había elegido ${ }^{77}$. Entre octubre de 1971 y diciembre de 1972 fueron dados de baja por "extinción de contratos" más de diecisiete mil enlaces; renunciaron más de seiscientos y fueron desposeídos de sus cargos veinticin$\mathrm{co}^{78}$. En ocasiones los trabajadores denunciaron la represión ante la OIT $^{79}$ y la necesidad de cambiar a los cargos sindicales, si estos defendían los intereses de la empresa ${ }^{80}$.

Las actitudes de los empresarios ante las elecciones sindicales no fueron homogéneas, mientras que unos veían que una representación real era mejor que una ficticia, otros denunciaron y pidieron ayuda al Gobierno para evitar «que al socaire de una falsa democracia los grupos de presión activista no se apoderen de una supuesta representatividad, tanto en la Organización Sindical como en

73. Véanse las Actas del Jurado de Empresa 122 (20 de abril de 1966) y 125 (12 de mayo de 1966), Actas del Jurado de Empresa de Perkins, (AHCO-FPM), carpetas $2 / 30$ y $2 / 32$.

74. "Acta 133 (24 de agosto de 1966)", Actas del Jurado de Empresa de Perkins, (AHCO-FPM), carpeta $2 / 41$, p. 1.

75. «Informe del Secretario General al IV Congreso Sindical de la OSE», Tarragona, 1968, p. 12.

76. ESTIVILI, Jordi y DE LA Hoz, Josep M., La cultura política dels treballadors a Catalunya (Estudi sobre les Eleccions Sindicals, 1944-1987), Barcelona, 1988, pp. 54-55.

77. Existen numerosos ejemplos, como el sucedido en la hueiga de Barreiros de diciembre de 1970, donde se procedió a la edetención y encarcelamiento de los hombres que han sido designados legalmente como jurados y enlaces que son,...", en COMISIÓN OBRERA DE CHRYSLER (BARREIROS), "Carta informativa de los trabajadores de Barreiros a la opinión pública", en APCE, fondo Movimiento Obrero, caja 84, carpeta 3/35.

78. BASCO, José M., "23.000 enlaces cesados", GDS, 22 (marzo 1973), p. 15.

79. «Sr. Presidente de la Organización Internacional del Trabajo». Escrito firmado por la Representación Social de FASA-RENAULT de Sevilla (cargos en activo), enero de 1974, en APCE, fondo Movimiento Obrero, caja 88, carpeta, 80.

80. LAS COMISIONES OBRERAS DE BAZÁN, "Declaración de CC.OO. La solución más democrática para la firma del Convenios, El Ferrol, 1de septiembre de 1970, en APCE, fondo Movimiento Obrero, caja 86 , carpeta, 6 . 
las Empresas.» ${ }^{81}$ Por último, una minoría optaron por negociar directamente con CC.OO. ${ }^{82}$ con el fin de evitar los conflictos.

\section{CAMBIOS EN LOS MERCADOS DE TRABAJO}

Tras la guerra civil, los mercados de trabajo tendieron a homogeneizarse hasta las medidas flexibilizadoras y desregulacionistas tomadas durante la transición democrática, diluyéndose las profundas diferencias existentes en los mismos ${ }^{83}$. El mercado se hizo nacional y se extendió la oferta de trabajo efectiva. La actitud del Estado fue muy regulacionista, el comportamiento de los empresarios, sobre todo desde 1959, reforzó la competitividad, lo que no impidió que las condiciones de trabajo se homogeneizasen. Los «mercados internos" ${ }^{84}$ crecieron debido al incremento de las inversiones de las empresas en formación, lo que dio lugar a una menor movilidad. Se mantuvieron los "mercados duales» ${ }^{85}$ y dentro de los mismos el sector primario creció. A lo que hay que añadir que el aumento del tamaño medio de las empresas favoreció la aparición de rigideces.

Las características institucionales, para el período analizado, del mercado de trabajo serían cuatro ${ }^{86}:$ la desvirtuación del sistema de contratación colectiva, la inexistencia de sindicatos libres, la existencia de restricciones legales al despido y la gran importancia de los componentes variables de la retribución salarial.

Desde 1958 y hasta 1975 , el crecimiento del empleo total fue muy escaso, menor que el de la población total, por lo que se incrementó la población dependiente, a la vez que se producía un sustancial aumento de la productividad $y$ de las inversiones de capital ${ }^{87}$. Como puso de manifiesto Enrique Fuentes

81. GABINETE TÉCNICO-ECONÓMICO SIDEROMETÚRGICO (SINDICATO PROVINCIAL DE METAL), Extractos de mayor consideración expuestos al Delegado Provincial de Sindicatos por la representación empresarial del más alto nivel, del Sindicato del Metal de Barcelona, Barcelona, 4 de febrero de 1971. Las empresas que suscribieron el documento fueron: AEG, CISPALSA, HARRY WALKER, MAOUINISTA TERRESTRE Y MARÍTIMA, ENASA (Pegaso), IBERIA RADIO, LÁMPARAS Z, SEAT Y ROCA RADIADORES, en APCE, fondo Movimiento Obrero, caja 88, carpeta 78/81, p. 2.

82. «En la celebración de un acto sobre «La problemática económica de Catalunya» a la que asistía López Rodó (...); Pere Durán Farell, directivo entonces de La Maquinista Terrestre y Marítima, declaró que para evitar más dificultades se había visto obligado a entablar conversaciones con Comisiones Obreras, dejando al lado el Sindicato oficial», Doblón, 3-9 de julio de 1976.

83. He realizado una descripción del funcionamiento de los mercados de trabajo en España entre 1938 y 1958 en mi artículo "Rupturas y continuidades en las relaciones laborales del primer franquismo, 1938-1958", en BARCIELA, Carlos (ed.), Autarquía y mercado negro. El fracaso económico del primer franquismo, 1939-1959, Barcelona, 2003, pp. 217-245.

84. Veáse DOERINGER, Peter B. y PIORE, Michael, Mercados internos de trabajo y análisis laboral, Madrid, 1985.

85. Véase PIORE, Michael J., "Notas para una Teoría de la Estratificación del Mercado de Trabajo", en TOHARA, Luis (compilación e introducción), El mercados de trabajo: Teoría y aplicaciones, Madrid, 1983, pp. 193-221.

86. MALO DE MOLINA, José Luis, ¿Rigidez oflexibilidad del mercado de trabajo? La experiencia española durante la crisis, Madrid, 1983, p. 9.

87. De 1965 a 1974 la formación bruta de capital creció un 9,1 por ciento de promedio en términos reales. Si a ello suma la caída de horas trabajadas al año por la población ocupada, el resultado 
Quintana: "la evolución de la economía española, en la etapa 1959-74 ocultó, tras sus tasas espectaculares de crecimiento y la posibilidad de emigración a Europa, sus importantes limitaciones para la creación de empleo." 88

Tabla 2. Evolución de la población activa, población ocupada y
número de empleos. España: 1955-1975

\begin{tabular}{|l|r|r|r|r|}
\hline & \multicolumn{1}{|c|}{$\mathbf{1 9 5 5}$} & \multicolumn{1}{|c|}{$\mathbf{1 9 6 2}$} & \multicolumn{1}{c|}{$\mathbf{1 9 6 9}$} & \multicolumn{1}{c|}{$\mathbf{1 9 7 5}$} \\
\hline POBLACIÓN ACTIVA & \multicolumn{1}{|c|}{11.970 .373} & 12.403 .366 & 13.015 .880 & 13.374 .633 \\
\hline Agricultura y pesca & 5.512 .567 & 4.772 .403 & 3.917 .601 & 3.075 .704 \\
\hline Industria & 2.589 .600 & 3.053 .648 & 3.417 .693 & 3.667 .376 \\
\hline Construcción & 771.662 & 919.990 & 1.122 .200 & 1.389 .688 \\
\hline Servicios & 3.096 .580 & 3.667 .415 & 4.558 .386 & 5.241 .865 \\
\hline PARADOS & 172.300 & 142.400 & 182.800 & 745.560 \\
\hline POBLACIÓN OCUPADA & 11.790 .073 & 12.260 .966 & 12.833 .080 & 12.629 .073 \\
\hline NÚMERO DE EMPLEOS & 11.964 .315 & 12.487 .429 & 13.076 .740 & 13.351 .182 \\
\hline
\end{tabular}

Elaboración propia. Fuente: BANCO DE BILBAO, Renta Nacional de España y su distribución provincial (Serie homogénea 1955-1975), Bilbao, 1978, pp. 116-117.

La población activa creció entre 1955 y 1975 un 11,7 por ciento y la ocupada un 7 por ciento. Esto supuso un aumento de las tasas de paro, sobre todo en los últimos años, pero de forma especial en 1975, aunque dicha tasa seguía siendo baja, un 3,8 por ciento. El hecho que explica porqué el paro no fue preocupante hasta mediados de la década de los setenta, fue sin duda la emigración de la fuerza de trabajo hacia Europa, que se inició a finales de los años cincuenta, convirtiéndose en masiva en la década siguiente y concluyendo bruscamente a mediados de los setenta ${ }^{89}$.

La tasa de actividad se mantuvo muy estable con una leve tendencia al crecimiento. La misma pasó de un 50,9 en 1964 a un 51,3 por ciento en 1975 . La de los varones descendió de un 83,2 a un 76,7 por ciento, mientras que la de la mujer se elevó, pasando de un 22,8 a un 28,1 por ciento.

El mercado de trabajo se vio sometido a una fuerte presión por la entrada de numerosos jóvenes, no obstante el propio mercado respondió creando empleo o facilitando la salida de mano de obra al exterior. Entre 1965 y 1974 «la economía española creó una media de 142.000 puestos de trabajo anuales, a través de

fue un claro incremento de la productividad. Véase BAIGE, Josep; MOLINAS, César y SEBASTIÂN, Miguel, La economía española 1964-1985: datos, fuentes y análisis, Madrid, 1987, pp. 26 y 57.

88. FuENTES QUINTANA, Enrique, "La crisis económica española», Papeles de Economía Española, 1 (1980), p. 99.

89. FERNÁNDEZ ASPERILLA, Ana, "La emigración como exportación de mano de obra: el fenómeno migratorio a Europa durante el franquismo", Historia Social, 30 (1998), pp. 65-66. 
un ciclo cuyo punto más bajo se encuentra en 1970 y los más altos en el boom de 1972 y $1973 »^{90}$.

Uno de los rasgos más sobresalientes de este período fue el fuerte aumento del empleo asalariado. En 1955 dicho empleo suponía el 54,2 por ciento, en 1975 el 71,1 por ciento. En la industria los asalariados pasaron, para el mismo período de tiempo, de un 73,1 a un 89,9 por ciento. En los servicios, de un 60,7 a un 75 por ciento. Este incremento tuvo un comportamiento cíclico, ya que en los años de mayor crecimiento del sector servicios aumentaba más el empleo no asalariado, mientras que en los años de menor crecimiento ocurría lo contrario. En cuanto a la construcción, sufría fuertes oscilaciones por su naturaleza coyuntural, siendo la presencia de asalariados muy elevada, en 1965 algo más del 89 por ciento. Pero cuando se comenzaron a sentir los primeros síntomas de crisis, se puso en marcha una paulatina pero constante sustitución de asalariados por trabajadores autónomos, lo que servía a los patronos para evadir las rigideces del mercado de trabajo.

El sector agrario representaba en 1955 el 46,1 por ciento del total de la población activa, en 1975 había descendido al 23 por ciento. El total de pérdidas en términos absolutos fue de casi dos millones y medio de efectivos. Este descenso, a diferencia de lo ocurrido en los demás sectores, no hizo variar el porcentaje de asalariados, que se movía en torno al 35 por ciento, aunque sí el de los pequeños agricultores y ganaderos. El éxodo rural provocó un envejecimiento de la población activa agraria. ${ }^{91}$

Tanto la industria como la construcción y los servicios vieron aumentar el número de trabajadores, especialmente este último sector que se incrementó en más de dos millones de activos. De hecho va a ser el sector servicios el que porcentualmente tenga un mayor peso en 1975 , el 39,2 por ciento, mientras veinte años antes representaba sólo un 25,9 por ciento.

A la hora de analizar la evolución de las diversas categorías ocupacionales entre 1964 y 1976 se aprecian con claridad dos grupos. Por un lado, los que pierden efectivos, los que se encuentran en retroceso: los pequeños propietarios agrícolas $(-8,9$ por ciento), obreros sin especializar $(-5,4$ por ciento), obreros agrícolas $(-3,4$ por ciento), autónomos en la industria y en los servicios $(-0,6$ por ciento) y, por último, el de los empresarios con asalariados $(-0,4$ por ciento). Por otro lado, las ocupaciones que aumentan sus efectivos: personal administrativo, comercial y técnico $(+7,8$ por ciento), personal de servicios $(+2,9$ por ciento) y los gerentes, directivos y encargados $(+1,2$ por ciento).

Estos cambios en la estructura ocupacional van a tener una notable influencia en la estructura de las clases sociales ${ }^{92}$, a la vez que ponen en evidencia la

90. AlbarRACín, Jesús, Las tendencias básicas de la población, el empleo y el paro en el período 1964 a 1980, Madrid, 1982, p. 25.

91. LEGUINA, Joaquín y NAREDO, José M., «Éxodo rural y envejecimiento de la población activa agrarian, Información Comercial Española, 496 (diciembre 1974), pp. 84-90.

92. Como afirma José Félix TEZANOS, los cambios habidos en la estructura ocupacional ponen de manifiesto el proceso de modernización de la sociedad española, la quiebra del viejo sistema 
similitud del proceso español con el habido en otros países de la Europa Occidental, aunque es cierto que en la mayor parte de los casos nuestro proceso fue tardío ${ }^{93}$.

La incapacidad estructural de la economía española para absorber su oferta de mano de obra, y la demanda de trabajadores de algunos países de Europa occidental dio lugar a una intensa corriente emigratoria externa paralela a la interna. La salida de mano de obra adulta fuera de nuestras fronteras no sólo supuso un respiro para nuestro mercado de trabajo ${ }^{94}$, sino la llegada de importantes cantidades de remesas, que junto a la inversión extranjera y las divisas que dejaba el turismo, constituyeron la base necesaria para el crecimiento económico y el mantenimiento del equilibrio presupuestario.

En 1956 se creó el Instituto Nacional de Emigración para encauzar y facilitar la emigración, a la vez que daba una cierta garantía a los emigrantes con la firma de convenios con otros países como fue el caso de Alemania, Suiza y Francia. También existía el deseo por parte de las autoridades españolas de allanar "el camino a la integración del país en Europa » ${ }^{95}$. Entre 1961 y 1975 emigraron a Europa más de dos millones y medio de españoles ${ }^{96}$, de los cuales el 56,5 por ciento eran emigrantes de temporada cuya estancia era inferior a los tres meses. Francia y la República Federal de Alemania fueron los principales países receptores. A partir de 1974 la emigración exterior sufrió un "frenazo" ${ }^{97}$, debido a los primeros síntomas de la crisis económica.

En conclusión, durante los años analizados se produjo un descenso considerable del sector agrario, la consolidación y el crecimiento de la industria y el proceso de terciarización. Dichos cambios se completan con el incremento de la población en edad de trabajar y una intensa emigración, que absorbió una parte sustancial de la mano de obra que la economía española era incapaz de emplear. A ello se añadiría una cada vez más numerosa población dependiente, hecho

de clases y su sustitución por uno nuevo, que responde plenamente a la estratificación propia de las modernas sociedades capitalistas. Este nuevo sistema, estaría condicionado por la creciente desruralización, el proceso de industrialización y terciarización, el incremento del número de asalariados y la mesocratización de la sociedad. Existiendo cada vez más una identificación de la población con las clases medias. Véase de dicho autor: Estructura de clases en la España actual, Madrid, 1975; y «Clases sociales», en GINER, Salvador (dir.), España. Sociedad y política, Madrid, 1990, pp. 109-141.

93. AMBRosiUs, Gerold y HubBaRD, William H., Historia social y económica de Europa en el siglo XX, Madrid, 1992, pp. 80-87.

94. Las tasas de paro nominales que se registraban en España a mediados de los años sesenta se situaban en torno al 3 por ciento, dicho porcentaje se elevaría casi al 11por ciento si se computase la mano de obra que emigró hacia Europa.

95. SERMET, Jean, "La Nouvelle Emigration Espagnole», Revue Geographique des Pyrénées et du SudOueste, XXXI (septiembre 1960), p. 297.

96. La cifra exacta de emigración asistida fue de 2.565 .832 , pero habría que añadir la emigración no controlada por las autoridades. Los datos provienen del cuadro 2.19 del libro coordinado por CARRERAS, Albert y TAFunell, Xavier, Estadísticas históricas de España. Siglos XIX-XX, Bilbao, 2005, p. 141.

97. Parra, Francisco, La emigración española en Francia 1962-1977, Madrid, 1981, p. 44. 
que tiene que ver con el aumento de la escolarización, y una mayor presencia de la mujer en los mercados de trabajo.

\section{SALARIOS Y NIVEL DE VIDA}

Desde finales de los años cincuenta, la progresiva adaptación de la economía española a las occidentales imponía una modificación sustancial del modelo salarial. Los cambios exigidos se concretaban en un incremento de los niveles salariales con el fin de hacer crecer la demanda efectiva y con ella la economía; es decir, aumentar el consumo, la productividad y evitar el paro tecnológico. A ello se unía la necesidad de flexibilizar el propio sistema salarial, rompiendo con el dirigismo estatal y posibilitando con ello la movilidad de la mano de obra y la adecuación de la misma a las nuevas relaciones técnicas de producción.

Las Encuestas de Salarios publicadas por el Instituto Nacional de Estadística para los años sesenta nos muestran la cada vez mayor importancia que tuvieron conceptos retributivos tales como "mejoras voluntarias", "primas e incentivos", "gratificaciones" y "horas extras». Especial incidencia tuvieron las horas extraordinarias, que se utilizaban para evitar la contratación de nueva mano de obra, debido a las dificultades que había para el despido. Dichos complementos llegaron a alcanzar, en algunas actividades, más del 50 por ciento de las retribuciones totales de los trabajadores ${ }^{98}$. En algunas empresas como la

"Basconia, los sueldos y jornales representaban un 60 por 100 sobre la retribución total de los trabajadores en sus diversas modalidades. El resto, se desdoblaba en un 32 por 100 a través de las denominadas atenciones sociales obligatorias, mientras un 8 por 100 era devengado en concepto de atenciones sociales voluntarias. Entre las primeras, la retribución incluía una gran variedad de conceptos, como el plus familiar, las pagas de beneficios, pagas extras, fiestas abonables y domingos, pluses de distancia, seguros sociales y de accidente de trabajo, etc. En el segundo grupo se incluían otros complementos, como las pagas extras de abril y octubre, pluses familiares a estas pagas, gratificaciones por año de servicio y buen comportamiento, etc. $)^{99}$

Un Decreto de 15 de febrero de 1962 estableció los conceptos retributivos exentos de consideración legal (prestaciones de carácter familiar, asignaciones de carestía de la vida, dotes por matrimonio,...), y una Orden de 22 de noviembre de 1973 recogió como computables otra serie de conceptos (descanso semanal, ausencias justificadas, interrupción del trabajo por causas ajenas a la voluntad del trabajador,...). Todo este entramado legal, complejo y farragoso, lo que trataba era de compensar los bajos salarios, incorporando nuevos complementos.

Durante los años analizados se produjeron tres hechos: el incremento del peso de las rentas salariales en el PIB, el aumento de los salarios reales y, por último, el cierre de los abanicos salariales.

98. Ministerio de ECONomía y COMERcio, Análisis estructural de los Convenios Colectivos 1980-1981, Madrid, 1982, p. 18.

99. Pérez, José A., Los años del acero..., p. 123. 
Los salarios incrementaron su participación en el PIB. Así, en 1964 representaba un 44,3 por ciento, y en 1975 el 53,7 por ciento. Esta tendencia se mantuvo hasta un año después de la firma de los Acuerdos de la Moncloa. Si analizamos la distribución funcional de la renta, se aprecia que son las rentas del trabajo y las públicas las que aumentan entre 1955 y 1975. Así las rentas de trabajo pasan de representar un 44,46 por ciento a un 62,76 y las rentas públicas de un 2,75 por ciento a un 3,22 . En cambio, las rentas mixtas y de capital disminuyen en dicho espacio de tiempo, pasando la primera de un 33,42 por ciento a un 21,9 , y la segunda de un 17,37 por ciento a un $12,12^{100}$.

La tasa media de crecimiento anual de los salarios nominales entre 1964 y 1965 fue de un 17,07 por ciento, siendo especialmente intensa en 1974 y 1975, años donde ya se siente la crisis económica y en los que el Gobierno pone en marcha la "política compensatoria", que tanto daño hizo a la economía española. En ese mismo período de tiempo el incremento de los salarios reales fue de un 7,5 por ciento como tasa media anual. El avance de éstos se mostró más estable que el de los nominales.

La evolución salarial, al no ser uniforme, provocó un cierre en el abanico, siendo la tasa de crecimiento tanto más alta cuanto más baja era la posición que ocupaba en la tabla. El cierre, aún siendo general, difería según los casos:

«(...) si tomamos el diferencial correspondiente a las dos categorías situadas en los extremos superior e inferior de retribuciones (técnicos titulados y peones), observamos que el descenso ha sido sustancial, pasando de un valor de 3,96 en 1964, a 2,7 en 1976, lo que significa que el salario medio de los primeros ha pasado de ser cuatro veces el de los segundos, a poco más de dos veces y media en estos años»101.

La OSE realizó un estudio ${ }^{102}$ que mostraba como el nivel de vida, en veinticinco años, se había duplicado y cómo las necesidades fundamentales que sólo estaban cubiertas en una tercera parte en 1950 llegaron a "estar cubiertas casi un $75 \%$ » veinticinco años después ${ }^{103}$. Aunque se debe indicar, como señalaba dicho estudio, que los niveles de bienestar social se situaban por detrás de los niveles de crecimiento económico.

$\mathrm{El}$ incremento de los salarios reales fue determinante para que se produjera la mejora del nivel de vida. Sin duda la negociación colectiva favoreció la subida de los salarios y más cuando el Jurado de Empresa era representativo de la voluntad de los trabajadores. Lo habitual en los convenios era ligar la subida salarial al índice del coste de la vida ${ }^{104}$. También se debe añadir que a partir de 1956 se

100. Los datos proceden del BANCO DE BILBAO, Renta Nacional de España y su distribución provincial (Serie homogénea (1955-1975), Bilbao, 1978, p. 89 (tabla R-29).

101. SÁEZ FeRNÁNDEZ, Felipe, "Salarios y segmentación del mercado de trabajo en España», en SECRETARÍA GENERAL TÉCnICA, El mercado de trabajo en España, Madrid, 1982, p. 99.

102. SERVICIO SINDICAL DE ESTADISTICA, Aproximación a un indice de evolución del nivel de vida para el periodo 1950-1975, Madrid, 1977.

103. Ibidem, p. 144.

104. «(...) los salarios establecidos se verán incrementados automáticamente con el porcentaje que determine el Instituto Nacional de Estadística, como índice de aumento del coste de vida para 
establecieron los salarios mínimos por zonas, y en 1963 se creó el salario minimo interprofesional garantizado.

\section{Tabla 3. Evolución de la estructura del presupuesto de consumo medio por persona (En tanto por cientos destinado a cada partida)}

\begin{tabular}{|l|c|c|c|c|}
\hline \multicolumn{1}{|c|}{ Concepto } & $\mathbf{1 9 5 8}$ & $\mathbf{1 9 6 4}$ & $\mathbf{1 9 6 8}$ & $\mathbf{1 9 7 3 / 7 4}$ \\
\hline Alimentación & 55,3 & 48,6 & 44,4 & 38,0 \\
\hline Vestido y calzado & 13,6 & 14,9 & 13,5 & 7,7 \\
\hline Vivienda & 5,0 & 7,4 & 10,3 & 12,0 \\
\hline Gastos de casa & 8,3 & 9,2 & 8,1 & 10,7 \\
\hline Otros gastos & 17,8 & 19,9 & 23,7 & 31,6 \\
\hline
\end{tabular}

Elaboración propia. Fuente: INSTITUTO NACIONAL DE ESTADÍSTICA, Encuesta de presupuestos familiares, años correspondientes.

Buena muestra del alza del nivel de vida lo constituye el desplazamiento que dentro de los gastos sufrieron las partidas correspondientes a los consumos "primarios" a favor de otros. Estos últimos fundamentalmente fueron bienes de consumo duraderos ${ }^{105}$.

La estructura del consumo, así como el volumen global del gasto medio variaban sustancialmente de una región o provincia a otra. Mientras que el País Vasco, Navarra, Madrid y Barcelona siempre se situaron por encima de la media; en cambio, Galicia, Asturias, Castilla la Vieja y León «en ningún indicador presenta un valor superior a la media nacional» ${ }^{106}$. También había notables diferencias entre el medio rural y urbano. Mientras en las ciudades el porcentaje del consumo dedicado a la alimentación, vestido y calzado representaba en $1973 / 74$ el 41,8 por ciento del gasto total, en los núcleos rurales se elevaba al 50,6 por ciento.

Pero dicha mejora en el nivel de vida estuvo acompañada de la aparición de nuevos problemas, como fue el de la vivienda en aquellas ciudades donde llegó masivamente la población proveniente del éxodo rural.

Madrid y su provincia", en Artículo $4 .^{\circ}$ del Convenio Sindical de la Industria Siderometalúrgica para la provincia de Madrid, 8 de febrero de 1965.

105. La producción de bienes de consumo duradero se multiplicó. En 1959 se fabricaron 37.763 automóviles; en 1976 la producción alcanzó 753.030, es decir, se multiplicó por veinte. Lo mismo ocurrió, para el mismo período de tiempo, con los televisores que se incrementaron en un 2.665 por ciento, los frigroríficos en un 3.039 por ciento, las lavadoras en un 1.207 por ciento y los teléfonos en un 1.600 por ciento. Una idea del cambio nos lo muestran datos como los que siguen: en 1960 la televisión sólo era disfrutada en el 1 por ciento de los hogares; trece años después, sólo un 15 por ciento de hogares carecían de la misma. Si nos referimos al frigrorífico, en 1960 el 86 por ciento de los hogares no disponian de él, mientras que en 1973 el 82 por ciento disponían del mismo. Estos datos proceden de estudio realizado por la FUNDACIón FOESSA, Estudios sociológicos sobre la situación de España, Madrid, 1976, p. 975.

106. Ibidem, p. 983. 
A finales de los años cincuenta se puso en marcha un Plan Nacional de Vivienda que favoreció sobre todo a las ciudades industriales (Madrid y Barcelona) y turísticas (Alicante y Valencia), pero el déficit de viviendas seguía siendo importante. Desde comienzos de la década de los sesenta hasta 1976 se construyeron más de cuatro millones cuatrocientas mil viviendas. En Madrid y su entorno existían, en 1956, más de cincuenta mil chabolas y en 1965 se calculaba que el déficit de viviendas ascendía a $985.004^{107}$.

Dos hechos caracterizaban la situación: en primer lugar que la iniciativa privada superaba a las promociones públicas, tendencia que se iría acentuando a lo largo de la década ${ }^{108}$; y, en segundo lugar, la transformación habida en el régimen de tenencia de las viviendas. En Madrid en 1950 el 88 por ciento del total de las viviendas eran alquiladas; en 1965 las viviendas alquiladas representaban un 54 por ciento. Este cambio supuso un incremento considerable de los nuevos propietarios, que pasaron de representar un 6 por ciento en 1950 a un 54 por ciento en 1965. Como consecuencia de ello se produjo un creciente endeudamiento de la clase trabajadora y de la clase media, que fijó su residencia de forma estable, repercutiendo todo ello en el mercado de trabajo.

Si bien aumentó la cobertura sanitaria cubierta por el seguro obligatorio de enfermedad hasta un 77,5 por ciento en 1975 , el servicio ofrecía un desigual desarrollo, ya que mientras en las provincias del norte existía una relativa abundancia de médicos, en las del sur la escasez era manifiesta, a lo que se añadía una baja calidad en la atención al paciente, la ausencia de medicina preventiva, la infrautilización de recursos y la falta de coordinación hospitalaria ${ }^{109}$.

En el campo educativo, pese a los avances que supuso la Ley General de Educación, también había significativos desequilibrios como se pone de manifiesto a la hora de analizar la procedencia social del alumnado, siendo la renta familiar la principal causa que determinaba el acceso a los centros docentes de grado medio y superior:

"La familia con renta baja no puede soportar sobre sí los gastos que origina la instrucción de sus hijos, no sólo por el coste directo (...), sino también por lo que podríamos llamar "lucro cesante» al impedir incorporar al hijo a la oferta de trabajo remunerado..110

Pero el hecho más negativo era el desigual reparto de la renta. La existencia de un sistema fiscal regresivo e ineficaz fue la principal causa de dicha situación, además en «el período 1964-1970 no se ha introducido ninguna corrección a la

107. Cáritas ESPaÑola, Plan de Promoción Social, Asistencia Social y Beneficencia de la Iglesia en España, I, Madrid, 1965, p. 120.

108. CASTELls, Manuel, «La crisis urbana de Madrid», en AYUNTAMIENTO DE MADRID, Madrid: Cuarenta años de desarrollo urbano 1940-1980, Madrid, 1981, p. 170.

109. García-DurÁn de LARA, José y PUIG BASTARD, Pedro, La calidad de vida en España, Madrid, 1980 , p. 293.

110. CÁRITAS ESPañola, Plan de Promoción..., op. cit., p. 93. 
desigual y poco equitativa distribución de la renta española»"11, situación que se prolonga hasta 1978. Lo cierto fue que el crecimiento de los años sesenta favoreció a las rentas más altas, y aunque no supuso que los asalariados sufrieran un empeoramiento de su posición en términos absolutos, sí lo sufrieron en términos relativos ${ }^{112}$.

Las rentas salariales se encontraban desigualmente repartidas: en 1973 el 60,2 por ciento de los trabajadores recibía el 36,1 por ciento de los ingresos, mientras en el escalón superior el 12,3 por ciento percibía el 29 por ciento ${ }^{113}$. Igual ocurría con respecto a la distribución de la renta personal disponible: en 1964 el 46,05 por ciento de los hogares recibía el 22,5 por ciento y en el extremo opuesto el 0,4 por ciento de los hogares disponía del 4,17 por ciento.

Aunque es evidente que se produjo un proceso de mejora general del nivel de renta, todavía quedaba mucho por hacer, dado que en 1965 «el $10 \%$ de la población, o sea, unos tres millones de personas aproximadamente, se encuentra en una situación de pobreza.» ${ }^{114}$ A lo que había que añadir el papel pasivo del Estado, ya que el gasto público con relación al PIB era muy bajo en España, tan sólo el 21,7 por ciento en 1970 y el 24,6 por ciento en 1975, mientras en la OCDE era del 32,4 y del 38 por ciento respectivamente y en el Mercado Común del 37 y 44,5 por ciento, en dichos años ${ }^{115}$.

Este hecho era consecuencia de la ausencia de un sistema fiscal moderno y progresivo, tampoco existía una política de renta, aunque sí medidas de protección social, por lo que no se puede hablar durante el franquismo de Estado del bienestar, que va a ser construido a lo largo de la transición y la democracia, sino de Estado de asistencia social.

111. ALCAIDE, Julio, "Así se distribuye la riqueza y la renta en la sociedad española», Revista Sindical de Estadistica, 4. ${ }^{\circ}$ trimestre de 1974.

112. ALBI, Emilio, «La distribución personal de la renta en España (1964-1967-1970)», Hacienda Pública Española, 32 (1975), p. 66.

113. InStITUTO NACIONAL DE EsTADÍsTICA, La Renta Nacional en 1975 y su distribución, Madrid, 1976, p. 208.

114. CÁRITAS ESPAÑola, Plan de Promoción..., op. cit., p. 155.

115. Rodríguez Cabrerizo, Gregorio, El Estado del bienestar en España: debates, desarrollo y retos, Madrid, 2004, p. 131; y también Papeles de Economía Española, 37 (1988). 